\section{Research Square}

Preprints are preliminary reports that have not undergone peer review.

They should not be considered conclusive, used to inform clinical practice, or referenced by the media as validated information.

\title{
Novel insights into the mechanisms by which IncRNAHOTAIR regulates migration and invasion in HeLa cells
}

peng zheng ( $\sim$ pengzh1984@wust.edu.cn )

Wuhan University of Science and Technology https://orcid.org/0000-0001-6595-7477

Zi cheng Lin Liu

Wuhan University of Science and Technology

\section{Fan $\mathrm{Hu}$}

Third Institute of Oceanography State Oceanic Administration

\section{Ying Chen}

College of life science,Yangtze University

\section{Zhuo Chen}

Shandong Provincial Key Laboratory of Plant Stress, College of Life Science, Shandong Normal Universtity

\section{Cun Tong Zhang}

College of Life Science and healthy, Wuhan University of Science and Technology

\section{Research}

Keywords: IncRNA, HOTAIR, miR-200a, YAP1, migration, invasion, RPL23

Posted Date: September 14th, 2020

DOI: https://doi.org/10.21203/rs.3.rs-73106/v1

License: (c) (i) This work is licensed under a Creative Commons Attribution 4.0 International License. Read Full License 


\section{Abstract \\ Background}

HOTAIR, as one of the few well-studied oncogenic IncRNAs, is involved in human tumorigenesis and is dysregulated in most human cancers. The transcription co-activator factor YAP1 is broadly expressed in many tissues, and promotes cancer metastasis and progression. However, the precise biological roles of HOTAIR and YAP1 in cancer cells remain unclear.

\section{Methods}

The expression levels of HOTAIR and YAP1 were measured by quantitative PCR (qPCR), immunoblotting. Wound-healing and transwell assays were used to examine the invasive abilities of HeLa cells. Luciferase reporter assays and CHIP were used to determine how YAP1 regulates RPL23. A xenograft mouse mode was used to assess the correlation between HOTAIR and YAP1 in vivo.

\section{Result}

In this study, we showed that HOTAIR regulates H3K27 histone modification in the promoter of miR-200a to mediate miR-200a expression byrecruiting EZH2. YAP1, as a potential target gene of miR-200a, aggravated the effects of miR-200a on the migration and invasion of HeLa cells. YAP1 activated the transcription of RPL23, which is a novel target of YAP1 transcriptional regulation. Agreement with this, the expression of YAP1 and RPL23 was dramatically decreased after injecting HeLa cells transfected with siHOTAIR in a xenograft mouse model.

\section{Conclusion}

These elucidates that HOTAIR, as an oncogenic IncRNA, recruits EZH2 to reduce miR-200a-3p expression via H3k27 trimethylation in the miR-200a-3p promoter. As a target gene of miR-200a-3p,YAP1 then promotes the migration and invasion of HeLa cells by mediating the downstream transcription of RPL23 which normally functions as a cancer-promoting factor. Accordingly, we propose a novel model of the molecular mechanism by which HOTAIR promotes the migration and invasion of cancer cells involving the miR-200a-3p/YAP1/RPL23 axis.

\section{Background}

In recent years, IncRNAs have gained widespread attention as a group of non-coding transcripts of $>200$ nucleotides that are involved in a wide range of biological processes(1-8). IncRNAs modulate gene expression at the transcriptional, post-transcriptional, translational, or post-translational levels (9-12). Within the last decade, HOTAIR has emerged as a key regulator of carcinogenesis and metastasis, a crucial oncogenic IncRNA contributing to different processes in several cancers (13-15). Howardet.al.firstuncovered a compelling mechanistic basis for HOTAIR in cancer, showing that it interacts with PRC2 to enhance H3K27 trimethylation, and decreases the expression of a large number of genes(16). HOTAIR, a negative prognostic factor, has been correlated with cancer cell proliferation, apoptosis, invasion, and metastasis in various cancer cell lines(17-20). Moreover, we showed that it may be involved in a diverse range of biological processes by mediating the expression of proteins, such as MKL1, OGFR, and vimentin (21-23). In our previous work, the well-established oncogene YAP1 was found to be significantly decreased after HOTAIR inhibition in HepG2 cells using proteomics technology (23). However, there is no evidence investigating whether HOTAIR can regulate YAP1 expression.

YAP is a transcription co-activator with a potential C-terminal transactivation domain (24) and an N-terminal region responsible for interaction with TEAD (25). However, YAP1 itself has no DNA binding activity; therefore, it must bind to DNAbinding transcription factors, such as TEAD1-4, RUNX2, and the ErbB4 cytoplasmic domain, to stimulate gene expression (24-26). Four TEAD genes are widely but variedly expressed in most human tissues. Moreover, YAP1 is widely overexpressed in many human tumors, and plays an essential role in cancer initiation, progression, and metastasis (27-30). YAP1 is phosphorylated and inhibited by large tumor suppressor $1 / 2$ kinases, which are important components of the Hippo pathway $(31,32)$. YAP1 phosphorylation leads to its cytoplasmic retention and reduced nuclear localization, preventing it from stimulating gene expression. The observed YAP1 nuclear-cytoplasmic shuttling indicates that the nuclear abundance of YAP1 plays a key role in tumor growth controlin vitro (33).

MiRNAs are a family of small endogenous non-coding RNAs molecular found in a diverse range of organisms, whichinvolved in many important biolocical processes such as cell growth, apoptosisand cancer progression (34-38). MiR-200a, as a member of miR-200 family, Loading [MathJax]/jax/output/CommonHTML/jax.js 
located in chromosome $1(39,40)$ and played a key role in the growth and development of tumors( $7,41-47)$. This miRNA has been implicated in epithelial to mesenchymal transition and tumor invasion by targeting the transcriptional factors of $\beta$-catenin, ZEB1, and ZEB2 $(48,49)$. Wang et.al.reported that miR-200a is a likely master regulator that affects the metastatic potential of cervical cancer by coordinately suppressing the expression of multiple genes important to cell motility(50). Epigenetic mechanisms are crucial regulators of cell type-specific genes, including miRNAs. Lukas et.al.found that the promoter of miR-200a is occupied by the polycomb-specific marker H3K27me3(51), while the silencing of miR-200a by histone methylation was shown to promote tumor growth and invasion in numerous types of human cancer(52-55). Enhancer of zeste homolog 2 (EZH2), as a methyltransferase and critical component of PRC2, is primarily responsible for H3K27 trimethylation. Meanwhile, HOTAIR recruits the PRC2 complex to regulate target gene expression via histone modifications. However, the precise relationship among HOTAIR, miR-200a, and H3K27 methylation was unclear.

In this study, we analyzed the correlations and potential role of HOTAIR and YAP1 in the migration and invasion of HeLa cells. We found that HOTAIR inhibition increased the expression of miR-200a-3p by preventingrecruiting of EZH2 to the miR-200a-3p promoter, thus decreasing H3K27 methylation. Furthermore, YAP1, as the targeted gene of miR-200a-3p, was investigated to promote the migration and invasion of HeLa cells. Additionally, RPL23 was first verified as the downstream transcriptionally regulated gene of YAP1 that promoted migration and invasion through regulating the expression of mutant p53 in HeLa cells. In agreement with these results, we showed that the expression of both YAP1 and RPL23 was decreased after injecting HeLa cells transfected with siHOTAIR in a xenograft mouse model.Taking all findings into account, we deduced that HOTAIR may promote migration and invasion of HeLa cells through the miR-200a3p/YAP1/RPL23 axis both in vitro and in vivo.

\section{Materials And Methods}

\section{Cell culture and siRNAtransfection}

The human cervical cancer cell line HeLa obtained from the American Type Culture Collection (ATCC) was grown in DMEM containing 10\% FBS, $2 \mathrm{mM}$ glutamine, $50 \mathrm{U} / \mathrm{ml}$ penicillin, and $50 \mathrm{mg} / \mathrm{ml}$ streptomycin at $37^{\circ} \mathrm{C}$ with $5 \% \mathrm{CO}_{2}$. A total of $40 \mathrm{nM}$ siRNA targeted against $\mathrm{HOTAIR}$ (siHOTAIR-I or siHOTAIR-II) or negative control siRNA (siNC) were transfected into HeLa cells using RNAi-mate. All siRNAs were purchased from GenePharma Co., Ltd., and siRNA sequences are listed in Table S1-1. HOTAIR expression levels were measured $48 \mathrm{~h}$ after transfection by qPCR (see below).

HeLa cells were also transfected with 40nM of siRNA targeted against YAP1 or RPL23 to silence gene expression. Again, cells were harvested $48 \mathrm{~h}$ after transfection, and protein expression was assessed by western blotting (see below).

MiR-200a-3p mimics, inhibitors, and negative controls were obtained from GenePharma, and their sequences are listed in Table S1-1. Cells cultured in 6-well plates were transfected miR-200a-3p mimics or inhibitors with 40nM/well according to the manufacturer's protocol. The negative controls consisting of random sequences had no detectable effects on human cell lines or tissues.

\section{RNA isolation and qRT-PCR}

Total RNA was extracted from cultured HeLa cells using TRIzol reagent (Invitrogen) according to the manufacturer's protocol. A Nanodrop 2000 spectrophotometer was used to measure the concentration of total RNA. RNA was then reverse-transcribed into first strand cDNA using the Revert Aid First Strand cDNA Synthesis Kit (Invitrogen). Quantitative PCR was carried out using the SYBR Green PCR Master Mix (Roche) and Light Cycler 480 Real-Time PCR system (Roche). GAPDH was used as the endogenous control gene to normalize expression of the target genes. Each sample was analyzed in triplicate. The thermal cycling program consisted of $95^{\circ} \mathrm{C}$ for 5 min followed by 40 cycles of $95^{\circ} \mathrm{C}$ for $10 \mathrm{~s}, 62^{\circ} \mathrm{C}$ for $45 \mathrm{~s}$, and $72^{\circ} \mathrm{C}$ for $30 \mathrm{~s}$. Melting curve data were then collected to verify the PCR specificity and the absence of primer dimers. All primer sequences are listed in Table S1-2.

MiRNAs were isolated using the mirVana miRNA isolation kit (Ambion) according to the manufacturer's protocol, and quantified using a Nanodrop 2000 spectrophotometer. Quantitative analysis of miR-200a-3p expression was performed using a Hairpin-it miRNA real-time PCR quantitation kit (GenePharma). Small nuclear RNA U6 was used as an internal control. Each sample was analyzed in triplicate.

\section{Plasmid constructs and expression}

The full-length YAP1 (NM_001130145) and RPL23 (NM_000978) cDNA were amplified by RT-PCR from total RNA isolated from HeLa cells, Loading [MathJax]/jax/output/CommonHTML/jax.js p vector pCDNA3.1/myc-his B (Invitrogen, USA). The BamH I and Xhol restriction sites were 
designed in the forward and reverse primers respectively. All the sequences of primers were listed in Table S1-3.

Plasmid was transfected into HeLa cells by Lipofection 2000 (Invitrogen) according to the manufacturer's instructions. After incubation for $6 \mathrm{~h}$, the medium was removed and replaced with normal culture medium for $48 \mathrm{hr}$. And the plasmid pCDNA3.1/myc-his B was used as the negative control. Proteins expression was assessed by Western blotting.

\section{Isolation of nuclear and cytoplasmic extracts}

Nuclear extraction was performed using an NE-PER Nuclear Cytoplasmic Extraction Reagent kit (Pierce, Rockford, IL, USA) according to the manufacturer's instructions. In brief, HeLa cells were washed twice with cold PBS and centrifuged at 500 ' $g$ for 5 min. The cell pellet was suspended in $200 \mu \mathrm{l}$ of cytoplasmic extraction reagent l, and vortexed vigorously on the highest setting for $15 \mathrm{~s}$, then incubated on ice for $10 \mathrm{~min}$. Next, $11 \mu \mathrm{l} \mathrm{CER} \mathrm{II} \mathrm{was} \mathrm{added,} \mathrm{vortexed} \mathrm{for} 5 \mathrm{~s}$, incubated on ice for $1 \mathrm{~min}$, and centrifuged at $16000^{\prime} \mathrm{g}$ for $5 \mathrm{~min}$. The supernatant (cytoplasmic extract) was immediately transferred to a clean pre-chilled tube. The insoluble pellet fraction, containing crude nuclei, was resuspended in $100 \mu \mathrm{l}$ nuclear extraction reagent by vortexing for $15 \mathrm{~s}$, incubating on ice for 10 min, then centrifuging at 16000 ' $g$ for 10 min. The supernatant (nuclear extract) was immediately transferred to a clean pre-chilled tube and used for subsequent experiments.

\section{Wound healing assay}

HeLa cells were seeded into 6-well plates and allowed to grow to 70\% confluency. Cell monolayers were then wounded by scratching a plastic pipette tip $(1 \mathrm{~mm}$ ) across the plate. Cellular debris was removed by washing with PBS. The number of cells migrating into the wound surface and the average distance of migrating cells were determined under an inverted microscope at designated time points.

\section{Matrigel cell invasion assay}

Transwell chambers (Corning, $8.0 \mu \mathrm{m}$ pore size) coated with Matrigel (BD Biosciences) were used to measure the invasiveness of cancer cells. In brief, $2 \times 10^{5}$ cells were plated in the upper chamber in serum-free media, and medium with $10 \%$ FBS was added to the bottom chamber. After $48 \mathrm{~h}$ incubation, the bottom of the chamber insert was fixed in methanol for 15 min and stained with Giemsa stain. Invading cells were photographed and counted under a microscope. Each membrane was divided into four quadrants and an average from four quadrants was calculated.

\section{Western blotting}

Protein extracts $(10 \mu \mathrm{g})$ prepared with RIPA lysis buffer were resolved on a $12 \%$ SDS-PAGE gel, and transferred to an Immobilon-P PVDF transfer membrane (Millipore) by electro-blotting. After blocking with $5 \%$ non-fat milk, membranes were incubated overnight at $4{ }^{\circ} \mathrm{C}$ with a 1:1000 dilution of the following primary antibodies: rabbit anti-YAP1 polyclonal, rabbit anti-RPL23 polyclonal, rabbit anti-mutant p53 polyclonal, rabbit anti-TBP (TATA binding protein) polyclonal, or mouse anti-GAPDH polyclonal. Blots were then incubated with peroxidaseconjugated IgG (ABclonal) diluted for $1 \mathrm{~h}$ at room temperature and then developed using a Super Signal West Pico kit (Pierce).

Immunoblots were scanned using an Image Scanner. Blot densitometry analysis was performed using Image $\mathrm{J}$ software. All analyses were performed in triplicate.

\section{Bioinformaticanalysis}

Potential YAP1 miRNA binding sites were predicted by computer-aided algorithms on the TargetScan Human (Release 7.0) (http://www.targetscan.org/vert_61/) (56), and PicTar (pictar.mdcberlin.de/) (57). The downstream transcriptional regulator of YAP1 was predicted using the Cistrome Data Browser (http://cistrome.org/db/)(58), which is a data portal for chromatin immunoprecipitation (ChIP)Seq and chromatin accessibility data in humans.

\section{Assay of luciferase activity}

Site-directed mutagenesis was used to change the binding sites of miR-200a-3p in the 3çUR of YAP1. The sequences of primer were shown in Table S1-4. For the reporter assay, a total of $20 \mathrm{nM}$ miR-200a-3p mimics or control miRNA were co-transfected with 0.1 $\mu \mathrm{g}$ pGL3-

Loading [MathJax]/jax/output/CommonHTML/jax.js

Page $4 / 18$ 
YAP1-3ÇUTR or pGL3-YAP1-3çUTR-mut into HeLa cells using Lipofectamine2000 (Invitrogen). Cells were harvested $48 \mathrm{~h}$ post-transfection using lysis buffer. Luciferase activities in cell lysates were determined using the Dual-Luciferase Reporter Assay System (Promega).

\section{ChIP}

The ChIP assay was performed using ChIP Assay Kit, following the manufacturer's instructions. Briefly, $1 \times 10^{7}$ HeLa cells were cross-linked with $1 \%$ formaldehyde for $10 \mathrm{~min}$ at $37^{\circ} \mathrm{C}$. Then, cells were scraped and resuspended with ice-cold PBS containing protease inhibitor cocktails (Pierce). Cells were then lysed and sonicated to shear DNA to an average length of 200-1000 bp. All procedures were performed on ice. Lysates were immunoprecipitated with an anti-YAP1 or anti-H3K27me3 antibody at $4^{\circ} \mathrm{C}$ overnight. Immunoprecipitation with an irrelevant normal IgG was used as a negative control. Immune complexes were then isolated with Protein A/G Sepharose beads at $4^{\circ} \mathrm{C}$ for 1 h. After washing, DNA fragments contained in immune complexes were purified and amplified by PCR. The sequences of primer were shown in Table S1-5.

\section{Immunofluorescence staining}

HeLa cells were grown on sterile glass-bottomed culture dishes, fixed in $4 \%$ formaldehyde for 30 min, and permeabilized in $1 \%$ FBS, $0.2 \%$ Triton-X100 on ice for $5 \mathrm{~min}$. After washing, cells were blocked with $1 \% \mathrm{BSA}$ for $1 \mathrm{~h}$ at room temperature, and then incubated with antibody at a dilution of 1:200 overnight. They were then incubated with Dylight 488-conjugated IgG $(\mathrm{H}+\mathrm{L})$ at a dilution of 1:100 for $2 \mathrm{~h}$ in the dark, then stained with DAPI for 15 min. Subsequently, cells were thoroughly washed three times with PBS and examined using an LSM 710 laser scanning confocal microscope (Zeiss, Germany).

\section{Xenograftmouse model}

Four-week-old female athymic BALB/c mice were purchased from Vital River Laboratories. For xenograft models, $2^{\prime} 10^{6} \mathrm{HeLa}$ cells transfected with siNC or siHOTAIR were subcutaneously injected in the right flank of BALB/c nude mice ( $n=5$ per group). Three weeks later, mice were sacrificed, tumors were homogenized, and proteins were extracted for western blotting. All animal procedures were performed in accordance with protocols approved by the Institutional Animal Care and Use Committee at the Institute of Wuhan University of Science and Technology.

\section{Statistical analysis}

Statistical analysis was performed using SPSS standard version 13.0 software. The independent Student's t-test was used to compare continuous variables between two groups. Data were expressed as means \pm SD from at least three independent determinations. Values of $P<0.05$ (or $P<0.01$ ) were considered statistically significant.

\section{Results}

\section{HOTAIR inhibition affected the expression of YAP1 in HeLa cells}

In our previous work (23), quantitative proteomics identified hundreds of differential expression proteins after HOTAIR inhibition in HepG2 cells, which contains the well-established oncogene YAP1. So, western blotting was used to analyze the whole protein expression of YAP1 after HOTAIR silencing in HeLa cells. As shown in Fig. 1A\&1B, YAP1 protein expression was significantly decreased after transfecting siHOTAIR. Additionally, YAP1 levels were dramatically reduced in both the cytoplasm and nucleus after HOTAIR knockdown (Fig. 1A\&1C \&1D). GAPDH and TATA-binding protein served as loading controls.

The migration and invasiveness of HeLa cells were further evaluated by the wound healing assay and Matrigel invasion assay. HOTAIR inhibition significantly decreased HeLa cell migration as determined by the wound healing assay (Fig. 1E\& 1F), while YAP1 inhibition clearly reduced cell migration compared with the negative control (Fig. 1E \&1F). Interestingly, co-transfection of HeLa cells with siHOTAIR and siYAP1 further suppressed the effect compared with the silencing of HOTAIR or YAP1 alone (Fig. 1E \&1F).

The number of invaded cells decreased significantly in HOTAIR knockdown cells compared with the negative control, while YAP1 inhibition reduced the invasion capability (Fig. 1G \&1H). Furthermore, the co-transfection of HeLa cells with siHOTAIR and siYAP1 aggravated the

Loading [MathJax]/jax/output/CommonHTML/jax.js 
effect of HOTAIR knockdown on cell invasion. Based on these results, we propose that YAP1 plays a critical role in the biological effects of HOTAIR on the migration and invasion of HeLa cells.

\section{Functional effects of YAP1 in HeLa cells}

YAP1, as a well-established oncogene, is a major effecter of the Hippo pathway and is closely associated with cancer(59-62). We evaluated the role of YAP1 in HeLa cells by the silencing/overexpression of YAP1 using the transient transfection of validated siRNAs and cDNAs. Plasmid pYAP1 was used to express YAP1 in HeLa cells,pCDNA3.1 was the negative control, and GAPDH served as the loading control. Western blotting was performed to determine YAP1 expression $48 \mathrm{~h}$ after transfection. As shown in Fig. 2A, YAP1 was significantly increased in HeLa cells compared with the control.Increased cell adhesion (Fig. 2B), cell migration, and invasion (Fig. 2C \& 2D\& 2E \& 2F)were all observed after YAP1 overexpression.YAP1 expression was significantly decreased $48 \mathrm{~h}$ after the transfection of YAP1 siRNA (Fig. $2 \mathrm{G}$ ), resulting in a reduction of cell adhesion (Fig. 2H), migration, and invasion (Fig. 2G-J). These results suggest that YAP1 has the potential to promote HeLa cell migration and invasion in HeLa cells.

\section{YAP1 is a potential target of miR-200a-3p}

We nextevaluated whether YAP1 was regulated by the defection of a specific miRNA in cervical carcinoma. A human miRNA chip microarray was used to detect differentially expression miRNAs following the transfection of HeLa cells with siRNA against HOTAIR. The expression of miR-200a-3p was significantly increased after HOTAIR inhibition (data not shown).

To investigate miRNA stargeting YAP1 that may be involved in the modulation of cell migration and invasion, we used the two common prediction algorithms TargetScan and PicTarto analyze the 3'UTR of YAP1. MiR-200a-3p was identified as targeting the 3'UTR of YAP1 by both algorithms. To further study whether miR-200a-3p expression was associated with the migration and invasion of cancer cells, we transfected miR-200a-3p mimics or an inhibitor intoHeLa cells. After transfecting miR-200a-3p mimics, miR-200a-3p expression levelswere significantly increased (Fig. 3A) and YAP1 protein expression was obviously decreased (Fig. 3B).Conversely, the miR-200a-3p inhibitor decreased miR-200a-3p RNA expression (Fig. 3C) and increased YAP1 expression (Fig. 3D).To further demonstrate the direct regulation of YAP1 by miR-200a-3p, we constructed luciferase reporters with the target sequences of wild-type (WT-UTR) and mutated YAP1 3'UTRs (mutUTR). We mutated six bases in the predicted sites of the YAP1 3'UTR (Fig. 3E). As shown in Fig. 3F, the luciferase activities of YAP1-mut-luc were dramatically increased compared with the negative control WT-UTR. All data suggested that miR-200a-3p, as a potential miRNAtargeting YAP1, degraded YAP1 by targeting specific sites in HeLa cells.

\section{Effect of miR-200a-3p on migration and invasion in HeLa cells}

To investigate whether miR-200a-3p has a role in mediating the biological roles between HOTAIR and YAP1, we firstly determined the functional roles of miR-200a-3p in the migration and invasion of HeLa cells. Compared with the negative control, the transfection of miR200a-3p mimics significantlyreduced migration and invasion in HeLa cells (Fig. 4A-D). Moreover, the co-transfection of HeLa cells with miR200a-3p mimics and YAP1 siRNA further decreased these effects compared with miR-200a-3p mimicsalone (Fig. 4A-D). In contrast, miR200a-3p inhibition dramatically increased cell migration and invasion (Fig. 4E-H). What is more, co-transfection of HeLa cells with anmiR200a-3p inhibitor and siYAP1 abrogated the effects of miR-200a-3p mimics on cell migration (Fig. 4E-H). These data suggested that miR200a-3p promotes migration and invasion in HeLa cells by regulating YAP1 expression.

\section{HOTAIR suppressed miR-200a-3p expression by H3 lysine 27 trimethylation}

HOTAIR is known to bind PRC2 (EZH2, EED, and SUZ12) at the 5'domain of HOTAIR(16), while EZH2 was reported to bind the miR-200a promoter and repress miR-200aexpression(54). We next investigated the relationship between HOTAIR and miR-200a-3p by examining the expression of miR-200a-3p after HOTAIR inhibition. As shown in Fig. 5A, miR-200a-3p was clearly increased after HOTAIR knockdown compared with negative control, and H3K27me3 expression was significantly decreased(Fig. 5B). We then performed ChIP assays to examine the effects of HOTAIR on the expression of H3K27me3 in the miR-200a-3p promoter. We found that H3K27me3 expression in the miR-200a-3p promoterwas significantly decreased to approximately $40 \%$ after HOTAIR inhibition in HeLa cells(Fig. 5C \& 5D). These data suggested that HOTAIR increases H3K27me3 levels at the miR-200a-3p promoter to suppress miR-200a-3p expression by recruiting EZH2 in HeLa cells.

\section{YAP1 promoted cancer cell migration and invasion by activating RPL23 transcription}

YAP1 and its paralog TAZ are co-transcriptional regulators downstream of the Hippo pathway. YAP1, as a co-activation factor, binds with TEAD to regulate the transcription of downstream genes(63). Here, the Cistrome Data Browser identified RPL23 as a novel target dniunntranm af thn trannnrintinnal maulatnr YAP1. To evaluate whether YAP1 regulates RPL23 transcription, we first altered the expression Loading [MathJax]/jax/output/CommonHTML/jax.js 
of YAP1 in HeLa cells by silencing/overexpressing using the transient transfection of validated siRNAs and cDNAs. Protein and mRNA levels of RPL23 were dramatically increased after the overexpression of YAP1 compared with controls(Fig. 6A \& 6B), while YAP1 inhibition by siRNA suppressed RPL23 protein and mRNA expression(Fig. 6C\& 6D). These findings were consistent with immunofluorescence staining after altering YAP1 expression in HeLa cells (Fig. 6G\&6H). We then used dual luciferase and ChIP assays to further investigate the relationship between YAP1 and RPL23. As shown in Fig. 6E, relative luciferase levels were clearly decreased after mutating the TEAD binding site on the RPL23 promoter, while YAP1 was highly enriched in the DNA fragments compared with negative control IgG immunoprecipitates (Fig. 6F).

RPL23 is a protein component of the 60 S large ribosomal subunit that was previously shown to be up-regulated in many cancers $(64,65)$, and was also emerging as a metastasis-related gene(66). As shown in Fig. 7A \& 7B, the wound width was significantly decreased after overexpressing RPL23 compared with controls. In contrast, RPL23 inhibition clearly increased the wound width of HeLa cells after transiently transfecting siRPL23 (Fig. 7C\& 7D). We next examined the effect of RPL23 on the invasion of HeLa cells using a Matrigel invasion assay. The number of invaded cells increased significantly in RPL23-overexpressingcells compared with the control, while RPL23 knockdown reduced the invasion capability (Fig. 7E-H).

Based on these results, we propose that YAP1 activates RPL23 transcription through TEAD binding with specific sequences on the RPL23 promoter to promote the migration and invasion of cancer cells.

\section{HOTAIR knock down reduced RPL23 expression}

To further investigate the role of HOTAIR in the migration and invasion of cancer cells, we measured the expression of YAP1 and RPL23 after HOTAIR knockdown in vitro and in vivo. The expression of YAP1, RPL23, and mutant p53 was significantly decreased after HOTAIR knockdown compared with the negative control (Fig. 8A), while YAP1 inhibition by siRNA reduced RPL23 and mutant p53 expression(Fig. 8B). Conversely, RPL23 and mutant p53 expression was clearly increased after overexpressing YAP1 (Fig. 8C). Furthermore, RPL23 overexpression dramatically increased the expression of mutant p53 (Fig. 8D), while the mutant p53 was significantly reduced after RPL23 inhibition compared with the negative control (Fig. 8E).

A xenograft mouse model was used to further validate in vitrofindings. The transient transfection of siHOTAIR was used to significantly suppress the tumorigenicity of HeLa cells. Subsequently, western blot analysis verified the reduction of YAP1 and RPL23 expression in HOTAIR knockdown xenografts compared with control xenografts(Fig. 8G), indicating that HOTAIR regulates the expression of YAP1 and RPL23 in vivo.

Based on these results, we propose that HOTAIR promotes migration and invasion in HeLacells by the miR-200a-3p/YAP1/RPL23 axis.

\section{Discussion}

As a new class of non-coding RNAs, IncRNAs have emerged as a crucial layer of gene regulation (13-15). HOTAIR is one of the few wellstudied IncRNAs and considerable attention has been given to determining its functions and identifying its target genes $(15,67,68)$.

Previous studies showed that HOTAIR regulates a diverse range of biological processes by modulating RNA or protein levels of hundreds of genes $(21,69)$. To better understand the precise molecular mechanism underlying the potential role of HOTAIR in cancer cells, it is essential to investigate the relationship between HOTAIR and its target genes.

We previously used quantitative proteomics technology to identify that HOTAIR up-regulates YAP1 expression in HeLa and HepG2 cells(11, 21). As shown in Fig. 1, the present study showed that YAP1 expression was significantly decreased after HOTAIR inhibition, especially in the nucleus. Moreover, the capability of migration and invasion were aggravated after co-transfecting with siYAP1 and siHOTAIR compared with HOTAIR alone in HeLa cells (Fig. 1E \& 1F). These results imply that YAP1 plays a pivotal role in the effects of HOTAIR on cell migration and invasion.

As a transcription co-activator factor, YAP1 is broadly expressed in many tissues, and promotes proliferation, migration, and invasion in several cancers by binding with the TEAD family to stimulate gene expression(25). YAP1 is overexpressed in numerous human cancers, such as gastric cancer, lung adenocarcinoma, ovarian cancer, and prostate cancer $(30,70,71)$. It exerts its tumor-supporting properties by up-regulating Jag-1 expression and activating the Notch pathway(28). Moreover, YAP1 has been defined as a prognostic biomarker and potential therapeutic target for gastric cancer, which promotes colony formation, cell growth, and metastasis both in vitro and in vivo(30). In agreement with these published data, we found that the overexpression of YAP1 increasedthe invasion and migration of HeLa cells, whilethe inhibition of YAP1 dramatically suppressed them. We confirmed this positive correlation between YAP1 and HOTAIR in a xenograft monce madol (Fin 8) Rv invectiratina the impact of HOTAIR inhibition and YAP1 knockdown in HeLa cells, we show that the effects of Loading [MathJax]/jax/output/CommonHTML/jax.js

Page $7 / 18$ 
HOTAIR knockdown oncancer cell migration and invasion can be mimicked by the respective manipulation of YAP1 expression. Importantly, HeLa cell migration and invasiveness were further decreased by the simultaneous inhibition of HOTAIR and YAP1.

MiR-200a, as a tumor suppressor, regulates the expression of several oncogenes in various cancers, while miR-200a overexpression significantly decreased cell motility in cervical cancer( $50,72,73)$. We previously used the Affymetrix miRNA assay to show that miR-200a was dramatically increased after HOTAIR knockdown in HeLa cells. In the present study, we further verified that HOTAIR knockdown enhanced miR-200a-3p expression in HeLa cells. Recent research has shown that the histone modification of H3K27 occupies the promoter of miR-200a and silences its expression $(51,52,54,55)$. EZH2, as a methyltransferase and critical component of PRC2, is primarily responsible for H3K27 methylation. Intriguingly, HOTAIR recruits the PRC2 complex to regulate target gene expression via histone modifications(16). However, the precise relationship between HOTAIR, miR-200a, and H3K27me3 was unclear.

To investigate this in the present study, we determined H3K27me3 expression using ChIP combined with RNA interference. As shown in Fig. 3, H3K27me3 expression in the promoter of miR-200a-3p was clearly decreased after HOTAIR inhibition compared with the negative control. We therefore speculated that HOTAIR regulates H3K27 trimethylationin the promoter of miR-200a-3p to mediate miR-200a-3p expression by recruiting EZH2, representing a novel compensation mechanism between HOTAIR and miRNAs. Our results also showed that increased miR-200a-3p expression significantly reduced the migration and invasion of HeLa cells. These effects were enhanced after inhibiting miR-200a-3p. Furthermore, YAP1 was down-regulated by miR-200a-3p targeting its 3'UTR, confirming it as a target gene of miR200a-3p in HeLa cells. Together, these data suggest that HOTAIR exerts its effects on the migration and invasion of cancer cells, at least in part, through the regulation of YAP1 by inhibiting miR-200a-3p in HeLa cells.

Ribosomal proteins (RPs) are components of ribosomal subunits that are ubiquitous RNAbinding proteins carrying out multiple auxiliary extraribosomal functions, and are moderately related to tumorigenesis $(74,75)$. When cancer cells undergo uncontrolled growth and proliferation, they increase the biosynthesis of ribosomal biogenesis and the production of RPs. Growing evidence suggests the existence of an association between RPL23 expression and tumor invasiveness and aggressiveness $(64,65,76)$. Indeed, RPL23 was reported to be up-regulated in human prostate cancer, lung cancer, and hepatocellular carcinoma $(66,77,78)$. RPL23 promoted the invasionof the metastatic lung adenocarcinoma cell line Anip973(66). However, the precise role of RPL23 in various fundamental processes remains elusive, and its tissue specificity may be more of a determinant ofits functions in the stressresponse(74). It is thus of great interest that we show that the role of YAP1 as an upstream transcriptional regulator of RPL23, at least in part, are mediated by the regulation of RPL23 expression in HeLa cells. The p53 mutation, which loses tumor suppressive functions and gains tumor-promoting activities(79), was reported to be associated with aggressive growth and increased recurrence rates for certain tumors(80). Here, we showed that RPL23 increased the expression of mutant p53 in HeLa cells. We therefore speculate that RPL23 enhances the migration and invasiveness of HeLa cells through promoting mutant p53 expression.

\section{Conclusion}

we propose a novel model depicting the precise molecular mechanism of HOTAIR in regulating the migration and invasion of cancer cells. We suggest that HOTAIR, as an oncogenic IncRNA, recruits EZH2 to reduce miR-200a-3p expression via H3k27 trimethylation in the miR200a-3p promoter. As a target gene of miR-200a-3p,YAP1 thenpromotes the migration and invasion of HeLa cells by mediating the downstream transcription of RPL23 which normally functions as a cancer-promoting factor. So we speculated that HOTAIR exerts its effects on the migration and invasion of cancer cells via the miR-200a/YAP1/RPL23/ signaling axis. Moreover, YAP1 may be a potential therapeutic target for the treatment of metastatic cervical cancer.

\section{Abbreviations}

IncRNA

Long non-coding RNA;

PRC2

polycomb repressive complex 2 ;

MKL1

Megakaryoblastic leukemia 1;

OGFR

opioid growth factor receptor;

YAP1

Yes-associated protein 1;

Loading [MathJax]/jax/output/CommonHTML/jax.js 
TEA domain;

EZH2

Enhancer of zeste homolog 2;

RPs

Ribosomal proteins;

HOTAIR

HoxC transcript antisense intergenic RNA;

RPL23

Ribosomal protein L23 ;

qPCR

quantitative Polymerase Chain Reaction;

CHIP

Chromatin Immunoprecipitation Assay;

DAPI

4'6-diamidino-2-phenylindole;

RNAi

RNA interference;

FBS

fetal bovine serum;

\section{Declarations}

\section{Ethical declarations}

All methodology and experiments in the study were approved by the ethics committee of WuHan University of Science and Technology.

\section{Consent for publication}

Not Applicable.

\section{Availability of supporting data}

All data generated during this study are included in this published article and its Additional files.

\section{Competing interests}

The authors declare that they have no competing interests.

\section{Founding}

This work was supported by the National Natural Science Foundation of China (NO. 31500622, 31970367), the program of Wuhan University of Science and technology (NO. 25011401).

\section{Acknowledgements}

The authors thank Sarah Williams, PhD, from Liwen Bianji, Edanz Group China (www.liwenbianji.cn), for editing the English text of a draft of this manuscript.

\section{Authors' contributions}


Author Contributions: PZ, ZC,TZ conceived and designed the experiments. PZ and CL performed the main experiments. FH and YC analyzed the data. PZ and ZC wrote the manuscript. All authors read and approved the final manuscript.

\section{References}

1. Hu WQ, Yuan BB, Flygare J, Lodish HF. Long noncoding RNA-mediated anti-apoptotic activity in murine erythroid terminal differentiation. Gene Dev. 2011;25(24):2573-8.

2. Meola N, Pizzo M, Alfano G, Surace EM, Banfi S. The long noncoding RNA Vax2os1 controls the cell cycle progression of photoreceptor progenitors in the mouse retina. Rna. 2012;18(1):111-23.

3. Wang $\mathrm{KC}$, et al. A long noncoding RNA maintains active chromatin to coordinate homeotic gene expression. Nature. 2011;472(7341):120-58.

4. Tsai MC, et al. Long Noncoding RNA as Modular Scaffold of Histone Modification Complexes. Science. 2010;329(5992):689-93.

5. Guttman M, et al. lincRNAs act in the circuitry controlling pluripotency and differentiation. Nature. 2011;477(7364):295-U260.

6. Tripathi V, et al. The Nuclear-Retained Noncoding RNA MALAT1 Regulates Alternative Splicing by Modulating SR Splicing Factor Phosphorylation. Mol Cell. 2010;39(6):925-38.

7. Bhan A, Mandal SS. (2014) Long Noncoding RNAs: Emerging Stars in Gene Regulation, Epigenetics and Human Disease. Chemmedchem 9.

8. Kino T, Hurt DE, Ichijo T, Nader N, Chrousos GP. Noncoding RNA gas5 is a growth arrest- and starvation-associated repressor of the glucocorticoid receptor. Sci Signal. 2010;3(107):2000568.

9. Klattenhoff CA, et al (Braveheart, a Long Noncoding RNA Required for Cardiovascular Lineage Commitment. Ce/l 152(3):570-583.

10. Xing Z, et al (IncRNA Directs Cooperative Epigenetic Regulation Downstream of Chemokine Signals. Cell 159(5):1110-1125.

11. Bodu, et al (A Cytoplasmic NF-кB Interacting Long Noncoding RNA Blocks IкB Phosphorylation and Suppresses Breast Cancer Metastasis.

12. Mchugh CA, et al (The Xist IncRNA interacts directly with SHARP to silence transcription through HDAC3. Nature 521(7551):232-236.

13. Zhang J, Zhang P, Wang L, Piao HL, Ma L. Long non-coding RNA HOTAIR in carcinogenesis and metastasis. Acta Biochim Biophys Sin. 2014;46(1):1-5.

14. $10.4161 /$ cc.9.17.13122

Wan Y \& Chang HY (HOTAIR: Flight of noncoding RNAs in cancer metastasis (Cell Cycle. 2010 Sep 1;9(17):3391-2. doi: 10.4161/cc.9.17.13122. Epub 2010 Sep 21.).

15. Gupta RA, et al. Long non-coding RNA HOTAIR reprograms chromatin state to promote cancer metastasis. Nature. 2010;464(7291):1071-6.

16. Tsai MC, et al (Long Noncoding RNA as Modular Scaffold of Histone Modification Complexes. Science 329(5992):689-693.

17. Geisler S, Coller J. RNA in unexpected places: long non-coding RNA functions in diverse cellular contexts. Nat Rev Mol Cell Bio. 2013;14(11):699-712.

18. Wahlestedt C. Targeting long non-coding RNA to therapeutically upregulate gene expression. Nat Rev Drug Discov. 2013;12(6):433-46.

19. Gibb EA, Brown CJ, Lam WL. (2011) The functional role of long non-coding RNA in human carcinomas. Mol Cancer 10.

20. Kogo R, et al. Long Noncoding RNA HOTAIR Regulates Polycomb-Dependent Chromatin Modification and Is Associated with Poor Prognosis in Colorectal Cancers (vol 71, pg 6320, 2011). Cancer Res. 2012;72(4):1039-9.

21. Zheng P, et al. Quantitative Proteomics Analysis Reveals Novel Insights into Mechanisms of Action of Long Noncoding RNA Hox Transcript Antisense Intergenic RNA (HOTAIR) in HeLa Cells. Mol Cell Proteomics. 2015;14(6):1447-63.

22. Zheng P, et al. (2018) LncRNA HOTAIR promotes cell migration and invasion by regulating MKL1 via inhibition miR206 expression in HeLa cells. Cell Commun Signal 16.

23. Wu Y, Xiong Q, Li ST, Yang X, Ge F. Integrated Proteomic and Transcriptomic Analysis Reveals Long Noncoding RNA HOX Transcript Antisense Intergenic RNA (HOTAIR) Promotes Hepatocellular Carcinoma Cell Proliferation by Regulating Opioid Growth Factor Receptor (OGFr). Mol Cell Proteomics. 2018;17(1):18-31.

24. Yagi R, Chen LF, Shigesada K, Murakami Y, Ito Y. A WW domain-containing yes-associated protein (YAP) is a novel transcriptional coactivator. Embo J. 1999;18(9):2551-62.

25. Vassilev A, Kaneko KJ, Shu H, Zhao Y, DePamphilis ML. TEAD/TEF transcription factors utilize the activation domain of YAP65, a Loading [MathJax]/jax/output/CommonHTML/jax.js

Page 10/18 
26. Komuro A, Nagai M, Navin NE, Sudol M. WW domain-containing protein YAP associates with ErbB-4 and acts as a co-transcriptional activator for the carboxyl-terminal fragment of ErbB-4 that translocates to the nucleus. J Biol Chem. 2003;278(35):33334-41.

27. Overholtzer $\mathrm{M}$, et al. Transforming properties of YAP, a candidate oncogene on the chromosome 11q22 amplicon. Proc Natl Acad Sci USA. 2006;103(33):12405-10.

28. Tschaharganeh DF, et al. Yes-associated protein up-regulates Jagged-1 and activates the Notch pathway in human hepatocellular carcinoma. Gastroenterology. 2013;144(7):1530-42.

29. Diep $\mathrm{CH}_{\text {, }}$ et al. (2012) Down-Regulation of Yes Associated Protein 1 Expression Reduces Cell Proliferation and Clonogenicity of Pancreatic Cancer Cells. PloS one 7(3).

30. Kang W, et al. Yes-associated protein 1 exhibits oncogenic property in gastric cancer and its nuclear accumulation associates with poor prognosis. Clin Cancer Res. 2011;17(8):2130-9.

31. Hao Y, Chun A, Cheung K, Rashidi B, Yang X. Tumor Suppressor LATS1 Is a Negative Regulator of Oncogene YAP. J Biol Chem. 2008;283(9):5496-509.

32. Oka T, Mazack V, Sudol M. Mst2 and Lats kinases regulate apoptotic function of Yes kinase-associated protein (YAP). J Biol Chem. 2008;283(41):27534-46.

33. Zhao B, et al. Inactivation of YAP oncoprotein by the Hippo pathway is involved in cell contact inhibition and tissue growth control. Gene Dev. 2007;21(21):2747-61.

34. Ambros V. The functions of animal microRNAs. Nature. 2004;431(7006):350-5.

35. Calin GA, Croce CM. MicroRNA signatures in human cancers. Nat Rev Cancer. 2006;6(11):857-66.

36. Kent OA, Mendell JT. A small piece in the cancer puzzle: microRNAs as tumor suppressors and oncogenes. Oncogene. 2006;25(46):6188-96.

37. Miska EA. How microRNAs control cell division, differentiation and death. Curr Opin Genet Dev. 2005;15(5):563-8.

38. Humphries B, Yang C. The microRNA-200 family: small molecules with novel roles in cancer development, progression and therapy. Oncotarget. 2015;6(9):6472-98.

39. Michael MZ, et al. Reduced accumulation of specific microRNAs in colorectal neoplasia. Molecular cancer research: MCR. 2003;1(12):882-91.

40. Altuvia Y, et al. Clustering and conservation patterns of human microRNAs. Nucleic acids research. 2005;33(8):2697-706.

41. Tang L, Zhang W, Su B, Yu B. (2013) Long noncoding RNA HOTAIR is associated with motility, invasion, and metastatic potential of metastatic melanoma. 2013(2013):251098.

42. Slattery ML, et al (An evaluation and replication of miRNAs with disease stage and colorectal cancer-specific mortality. International Journal of Cancer 137(2):428-438.

43. Cristóbal I, et al. (Deregulation of miR-200b, miR-200c and miR-429 indicates its potential relevant role in patients with colorectal cancer liver metastasis. Journal of Surgical Oncology 110(4):484-485.

44. Jia C, et al. miR-200a-3p plays tumor suppressor roles in gastric cancer cells by targeting KLF12. Artificial cells nanomedicine biotechnology. 2019;47(1):3697-703.

45. Jiang $\mathrm{JH}_{\text {, }}$ et al. MicroRNA-200a promotes proliferation and invasion of ovarian cancer cells by targeting PTEN. Eur Rev Med Pharmacol Sci. 2018;22(19):6260-7.

46. Zeng X, et al. FEN1 mediates miR-200a methylation and promotes breast cancer cell growth via MET and EGFR signaling. FASEB journal: official publication of the Federation of American Societies for Experimental Biology. 2019;33(10):10717-30.

47. Zhao ZB, Chen F. (2019) Long Noncoding RNA MALAT1 Regulates Hepatocellular Carcinoma Growth Under Hypoxia via Sponging MicroRNA-200a. 60(8):727-734.

48. Saydam O, et al. Downregulated microRNA-200a in meningiomas promotes tumor growth by reducing E-cadherin and activating the Wnt/beta-catenin signaling pathway. Mol Cell Biol. 2009;29(21):5923-40.

49. Xia H, et al. miR-200a-mediated downregulation of ZEB2 and CTNNB1 differentially inhibits nasopharyngeal carcinoma cell growth, migration and invasion. Biochem Biophys Res Commun. 2010;391(1):535-41.

50. Hu X, et al. A microRNA expression signature for cervical cancer prognosis. Cancer Res. 2010;70(4):1441-8.

51. Vrba L, Garbe JC, Stampfer MR, Futscher BW. Epigenetic regulation of normal human mammary cell type-specific miRNAs. Genome Res. 2011;21(12):2026-37.

52. Castilla MA, et al. MicroRNA-200 family modulation in distinct breast cancer phenotypes. PloS one. 2012;7(10):e47709.

Loading [MathJax]/jax/output/CommonHTML/jax.js

Page $11 / 18$ 
53. Neves R, et al. Role of DNA methylation in miR-200c/141 cluster silencing in invasive breast cancer cells. BMC Res Notes. $2010 ; 3: 219$.

54. Ning X, et al. DNMT1 and EZH2 mediated methylation silences the microRNA-200b/a/429 gene and promotes tumor progression. Cancer Lett. 2015;359(2):198-205.

55. Enkhbaatar Z, et al. KDM5B histone demethylase controls epithelial-mesenchymal transition of cancer cells by regulating the expression of the microRNA-200 family. Cell Cycle. 2013;12(13):2100-12.

56. Agarwal V, Bell GW, Nam JW, Bartel DP. (2015) Predicting effective microRNA target sites in mammalian mRNAs. Elife4.

57. Chen K, Rajewsky N. Natural selection on human microRNA binding sites inferred from SNP data. Nat Genet. 2006;38(12):1452-6.

58. Mei S, et al. Cistrome Data Browser: a data portal for ChIP-Seq and chromatin accessibility data in human and mouse. Nucleic acids research. 2017;45(D1):D658-62.

59. Camargo FD, et al. YAP1 increases organ size and expands undifferentiated progenitor cells (vol 17, pg 2054, 2007). Curr Biol. 2007;17(23):2094-4.

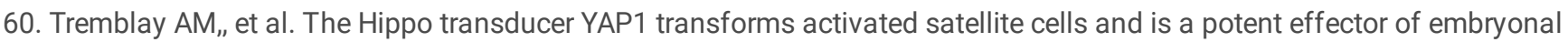
rhabdomyosarcoma formation. Cancer Cell. 2014;26(2):273-87.

61. Huang J, Wu S, Barrera J, Matthews K, Pan D. The Hippo signaling pathway coordinately regulates cell proliferation and apoptosis by inactivating Yorkie, the Drosophila Homolog of YAP. Cell. 2005;122(3):421-34.

62. Dong J, et al. Elucidation of a universal size-control mechanism in Drosophila and mammals. Cell. 2007;130(6):1120-33.

63. Zhao B, et al. TEAD mediates YAP-dependent gene induction and growth control. Genes Dev. 2008;22(14):1962-71.

64. Jin A, Itahana K, O'Keefe K, Zhang Y. Inhibition of HDM2 and activation of p53 by ribosomal protein L23. Mol Cell Biol. 2004;24(17):7669-80.

65. Meng X, et al. RPL23 Links Oncogenic RAS Signaling to p53-Mediated Tumor Suppression. Cancer Res. 2016;76(17):5030-9.

66. Liu F, Li Y, Yu Y, Fu S, Li P. Cloning of novel tumor metastasis-related genes from the highly metastatic human lung adenocarcinoma cell line Anip973. J Genet Genomics. 2007;34(3):189-95.

67. Wan Y, Chang HY. HOTAIR: Flight of noncoding RNAs in cancer metastasis. Cell Cycle. 2010;9(17):3391-2.

68. Lv DW, et al. Integrative Network Analysis of the Signaling Cascades in Seedling Leaves of Bread Wheat by Large-Scale Phosphoproteomic Profiling. J Proteome Res. 2014;13(5):2381-95.

69. Gibb EA, Brown CJ, Lam WL. The functional role of long non-coding RNA in human carcinomas. Mol Cancer. 2011;10:38.

70. Zhao B, et al. Inactivation of YAP oncoprotein by the Hippo pathway is involved in cell contact inhibition and tissue growth control. Genes Dev. 2007;21(21):2747-61.

71. Xu MZ, et al. Yes-associated protein is an independent prognostic marker in hepatocellular carcinoma. Cancer. 2009;115(19):4576-85.

72. Jia W, et al. Expression profile of circulating microRNAs as a promising fingerprint for cervical cancer diagnosis and monitoring. Molecular clinical oncology. 2015;3(4):851-8.

73. Rao Q, Zhou H, Peng Y, Li J, Lin Z. Aberrant microRNA expression in human cervical carcinomas. Medical oncology. 2012;29(2):12428.

74. de Las Heras-Rubio A, Perucho L, Paciucci R, Vilardell J, LLeonart ME. Ribosomal proteins as novel players in tumorigenesis. Cancer Metastasis Rev. 2014;33(1):115-41.

75. Kim TH, Leslie P, Zhang Y. Ribosomal proteins as unrevealed caretakers for cellular stress and genomic instability. Oncotarget. 2014;5(4):860-71.

76. Wang J, et al. (2020) Triptolide interrupts rRNA synthesis and induces the RPL23-MDM2-p53 pathway to repress lung cancer cells. Oncol Rep 30(10).

77. Kondoh N, et al. Enhanced expression of S8, L12, L23a, L27 and L30 ribosomal protein mRNAs in human hepatocellular carcinoma. Anticancer Res. 2001;21(4A):2429-33.

78. Bee A, et al. siRNA knockdown of ribosomal protein gene RPL19 abrogates the aggressive phenotype of human prostate cancer. PloS one. $2011 ; 6(7): 22$.

79. Di Agostino S. (2020) The Impact of Mutant p53 in the Non-Coding RNA World. Biomolecules 10(3).

80. Vijayakumaran R, Tan KH, Miranda PJ, Haupt S, Haupt Y. (2015) Regulation of Mutant p53 Protein Expression. Front Oncol 5(284).

\section{Figures}


A

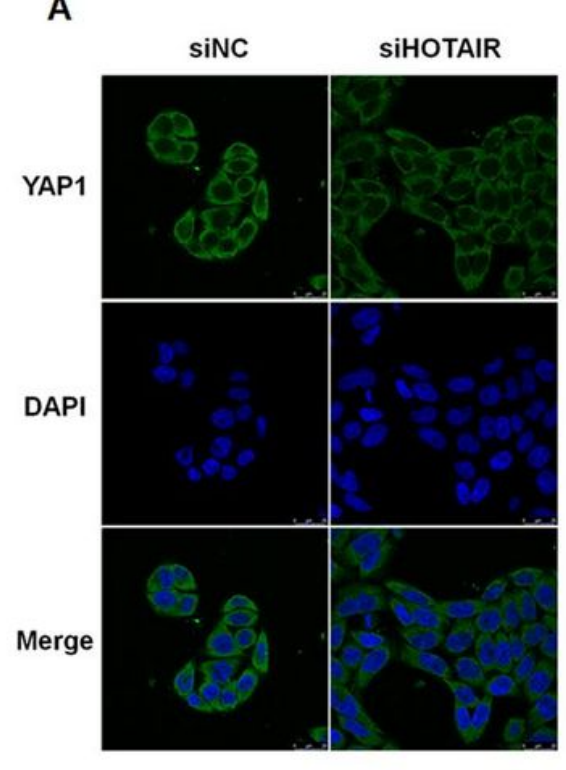

B

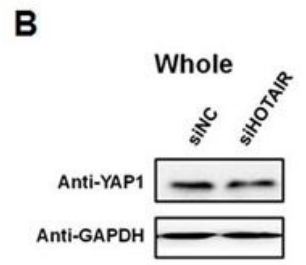

C

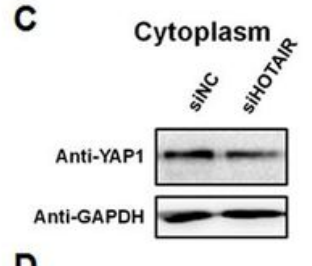

D

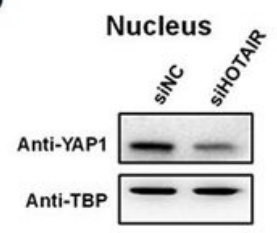

E

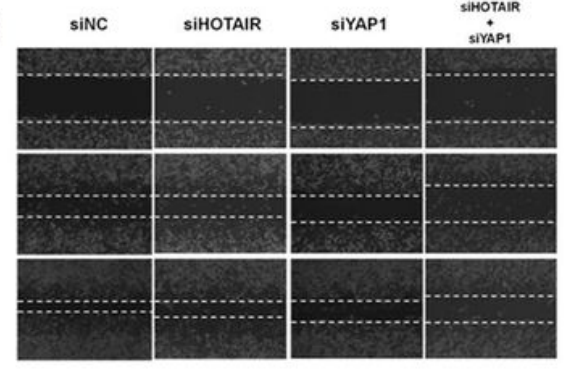

$\mathbf{F}$

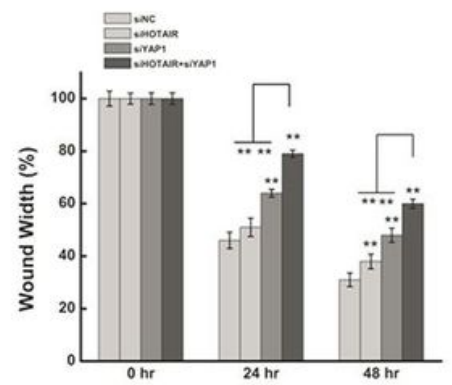

G

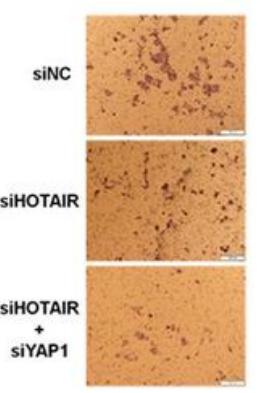

H

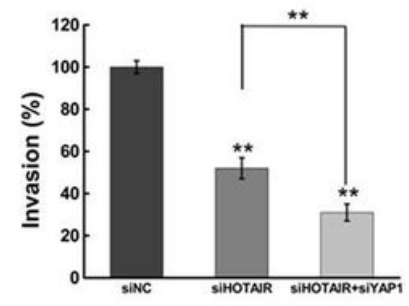

\section{Figure 1}

HOTAIR inhibition affect the expression and distribution of YAP1 in HeLa cells. (A). Representative images showing the distribution of YAP1 in HeLa cells after HOTAIR knockdown under confocal microscopy. (B). The whole YAP1 expression was measured after HOTAIR inhibition by western blotting. (C) (D). Western blotting analysis the expression of YAP1 in cytoplasm or nucleus after HOTAIR inhibition. (E).The effect of knockdown HOTAIR or/and YAP1 on cell migration was determined by wound healing assay. (F). Quantification of the wound healing assay. (G).The effect of knockdown HOTAIR or/and YAP1 on cell invasion was determined in a Boyden chamber assay. $(\mathrm{H})$. And the number of cells on the underside of the filter was determined and significantly $(P<0.05)$ changed invasion is indicated. Data are presented as means \pm S.D. and represent results from three independent experiments. Statistically significant differences are indicated: ${ }^{*}, P<0.05 ; * \star$, $\mathrm{P}<0.01$ (Student's $\mathrm{t}$ test). 

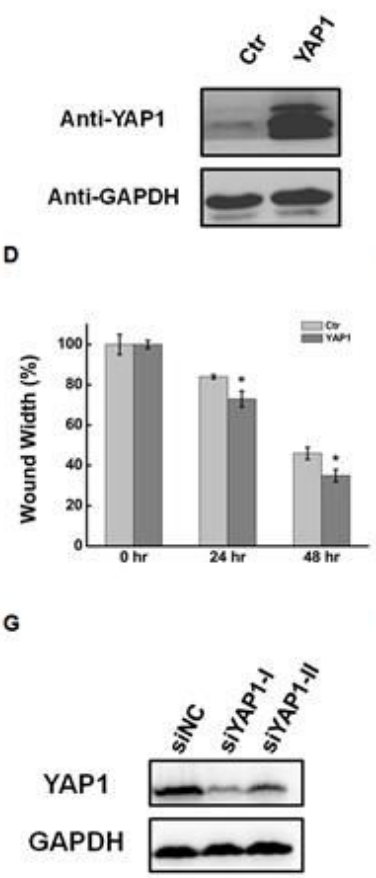

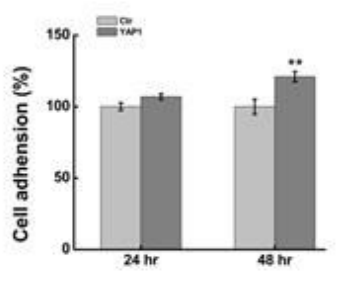

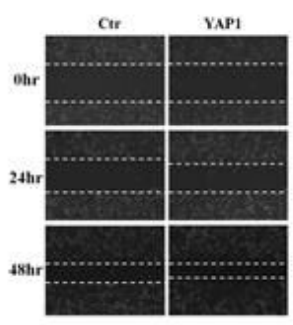

$\mathbf{F}$
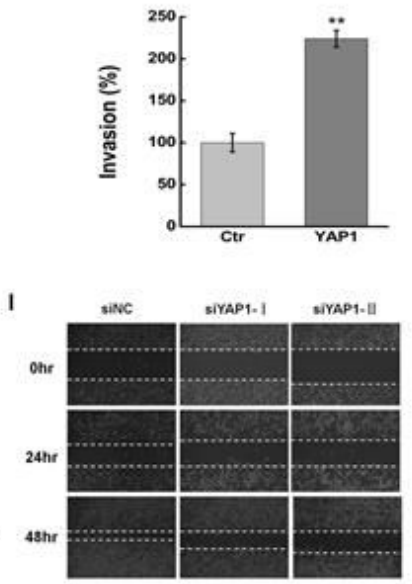

L

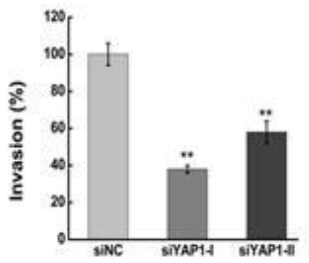

Figure 2

The function effects of YAP1 in HeLa cells. (A).HeLa cells were transfected with pYAP1 or pCDNA3.1. The YAP1 expression level was determined by western blotting at $24 \mathrm{hr}$ and $48 \mathrm{hr}$ after transfection. GAPDH serves as the loading control. (B). The cell adhension was determined after transfecting YAP1 at $24 \mathrm{hr}$ and $48 \mathrm{hr}$. (C). The effect of YAP1 on cell migration was determined by wound healing assay. (D). Quantification of the wound healing assay. (E). The effect of YAP1 on cell invasion was determined in a Boyden chamber assay. (F). The number of cells on the underside of the filter was determined and significantly $(P<0.05)$ changed invasion is indicated. $(G)$. Western blots analysis of the YAP1 protein expression at $48 \mathrm{hr}$ after transfected with siYAP11 or siNC. $(\mathrm{H})$. The cell adhension was determined after silencing YAP1 at $24 \mathrm{hr}$ and $48 \mathrm{hr}$. (I). The effect of YAP1 inhibition cell migration was determined by wound healing assay. (J). Quantification of the wound healing assay. (K). The effect of YAP1 knockdown on cell invasion was determined in a Boyden chamber assay. $(L)$. The number of cells on the underside of the filter was determined and significantly $(P<0.05)$ changed invasion is indicated. Data are presented as means \pm S.D. and represent results from three independent experiments. Statistically significant differences are indicated: *, $\mathrm{P}<0.05 ; * \star, \mathrm{P}<0.01$ (Student's $\mathrm{t}$ test). 
A

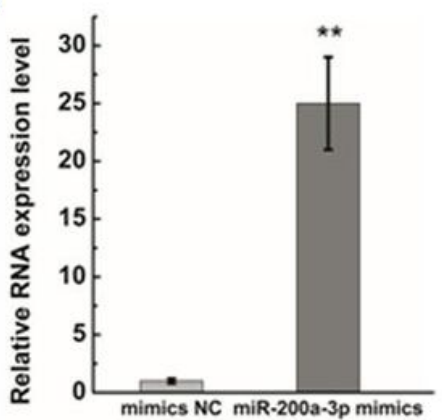

B

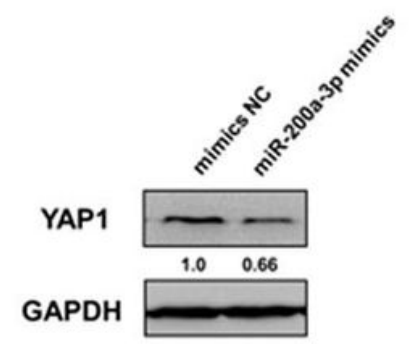

C

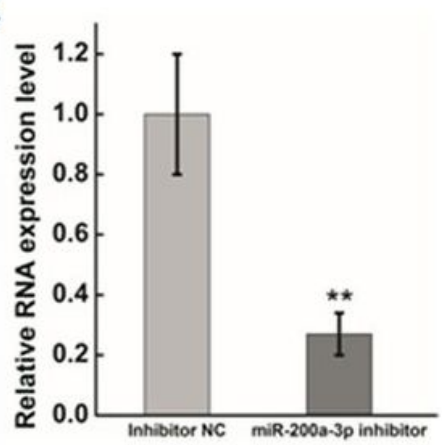

D

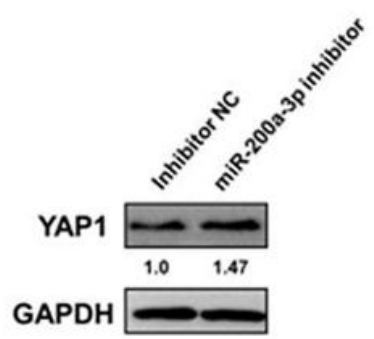

E

Position 3090-3096 of YAP1 3' UTR

5 ...AGAAUUCAUACCAAUCAGUGUUG...

Mutation

5...AGAAUUCAUACCAAUAGAGGAUG...

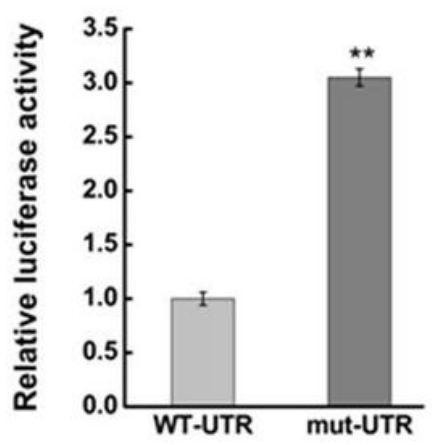

Figure 3

YAP1 is a potential target of miR-200a-3p. (A). HeLa cells were transfected with miR-200a-3p mimics or NC for 48 hrs. The abundance of miR-200a-3p expression was determined by qRT-PCR. (B).Western blots analysis of the YAP1 protein expression at $48 \mathrm{hr}$ after transfecting with miR-200a-3p mimics or NC. (C). qRT-PCR was used to measure the efficiency of miR-200a-3p inhibition after transfection at $48 \mathrm{hr}$. (D). Western blots analysis of MKL1 expression at $48 \mathrm{hr}$ after transfecting with miR-200a-3p inhibitor or NC. (E). Diagram of YAP1-3

UTRconta $\in \in$ grep or terconstructs. $(F)$. Inluc if eraseassaysusingHeLacells, tranectionofmiR-200a-3p and YAP1-3 UTR-mut increased the luciferase activities compared with transfection of miR-200a-3p and YAP1-3 'UTR-WT. Data are presented as means \pm S.D. and results are from one representative experiment of at least three. ${ }^{*} \mathrm{P}<0.05$; $* * \mathrm{P}<0.01$ (Student's $t$ test).

A

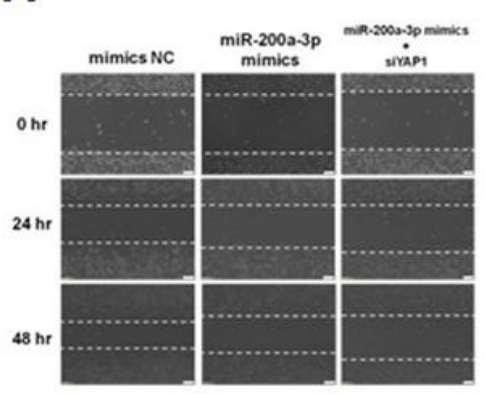

E

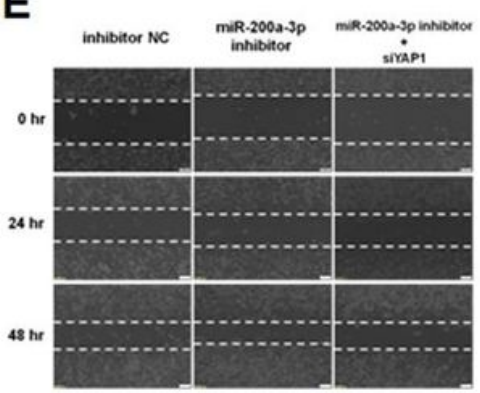

B

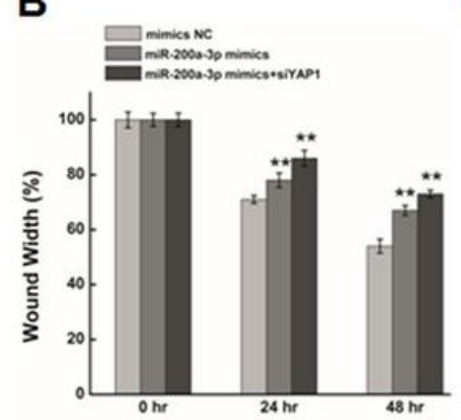

F

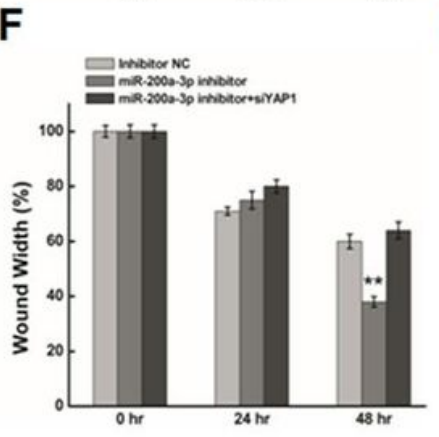

C

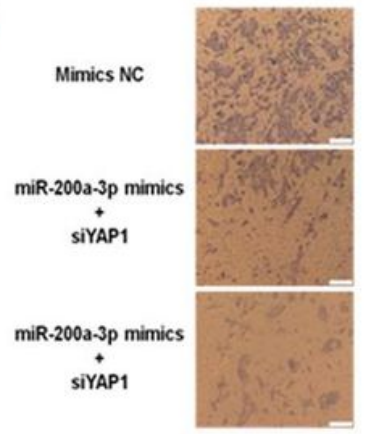

G

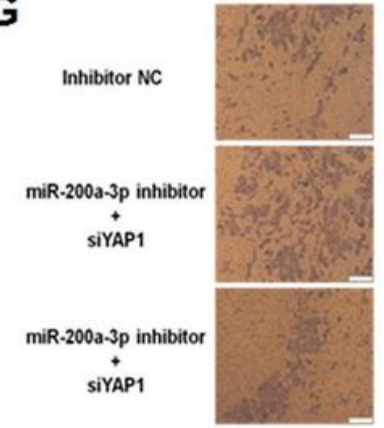

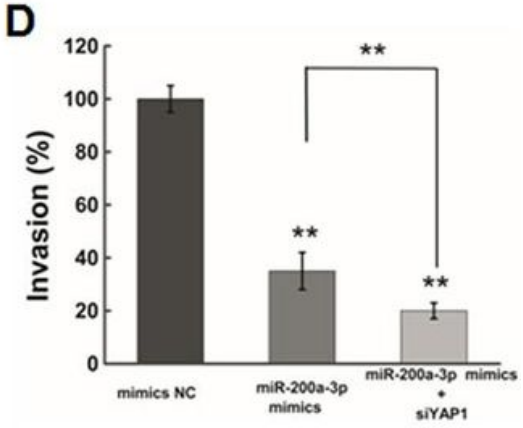

H

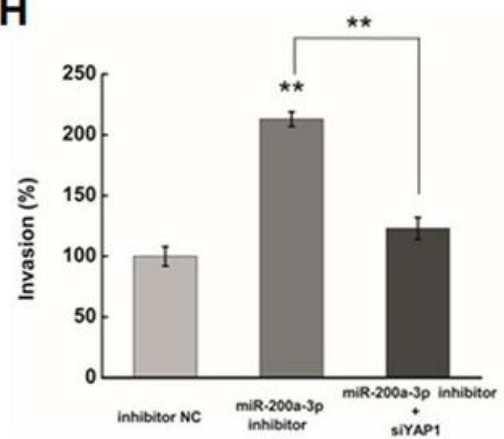

\section{Figure 4}


Effect of miR-200a-3p on cells migration and invasion in HeLa cells. (A) (E). The effect of miR-200a-3p on cell migration was determined by wound healing assay. (B) (F). Quantification of the wound healing assay. (C) (G). The effect of miR-200a-3p on cell invasion was determined in a Boyden chamber assay. (D) $(H)$. The number of cells on the underside of the filter was determined and significantly $(P<$ 0.05 ) changed invasion is indicated. Data are presented as means \pm S.D. and represent results from three independent experiments. Statistically significant differences are indicated: ${ }^{*}, \mathrm{P}<0.05 ; * *, \mathrm{P}<0.01$ (Student's $\mathrm{t}$ test).

A

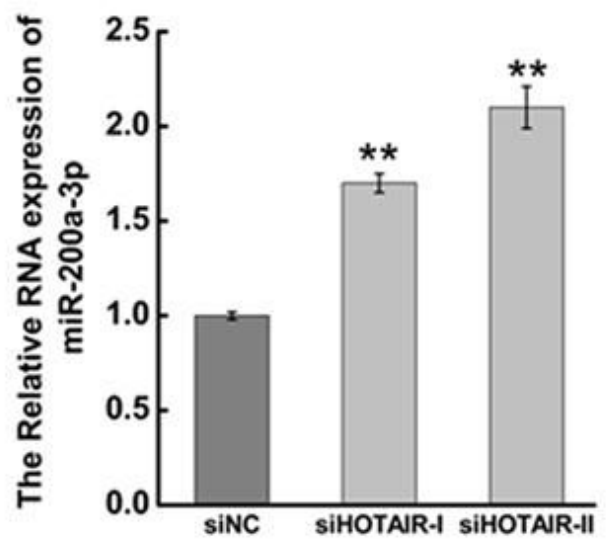

C

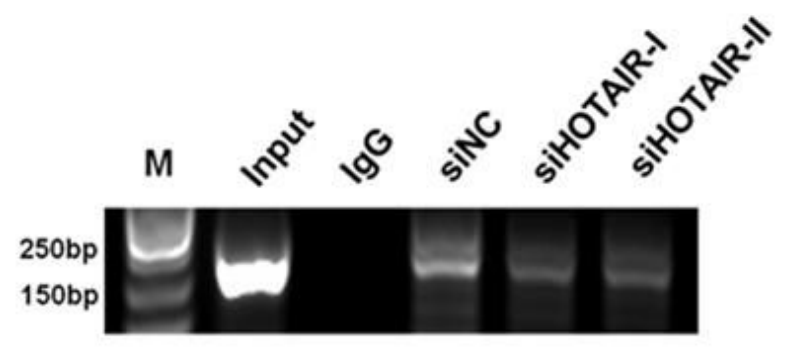

B

H3K27me3

\section{GAPDH}
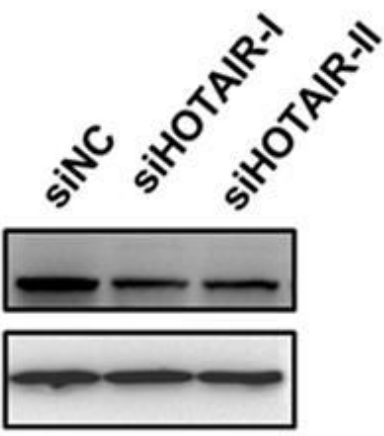

D

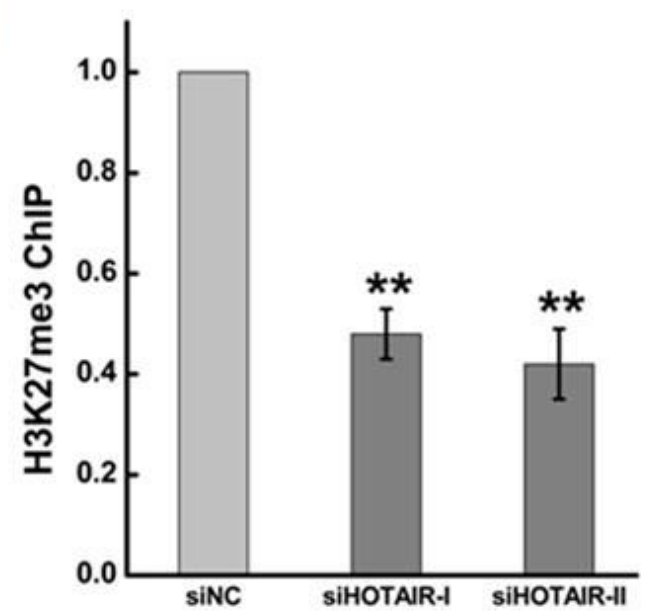

\section{Figure 5}

HOTAIR suppressed miR-200a-3p expression by H3 lysine 27 trimethylation. (A). The RNA expression of miR-206 after transfecting siHOTAIR at $48 \mathrm{hr}$ by qRT-PCR. The expression level of miR-206 was normalized to U6. (B). Western blotting was used to measured the expression of H3K27 trimethylation after inhibiting HOTAIR at $48 \mathrm{hr}$. GAPDH was used as an internal control. (C). After transfecting with siHOTAIR or siNC, cells were lysed and incubated with $\mathrm{H} 3 \mathrm{~K} 27 \mathrm{me} 3$ monoclonal antibody at $4^{\circ} \mathrm{C}$ overnight. Chromatin immunoprecipitation (ChIP) assay was used to determined the H3K27me3 expression level occupied on the promoter of miR-200a-3p in HeLa cells. (D). Quantification of the ChIP assay. Data are presented as means \pm S.D. and represent results from three independent experiments. Statistically significant differences are indicated: *, $\mathrm{P}<0.05 ; * \star, \mathrm{P}<0.01$ (Student's $\mathrm{t}$ test). 
A

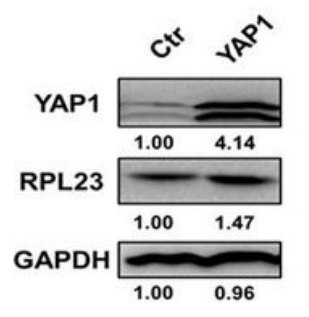

C

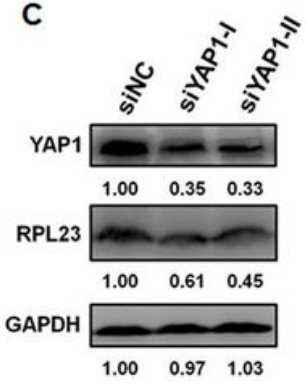

B

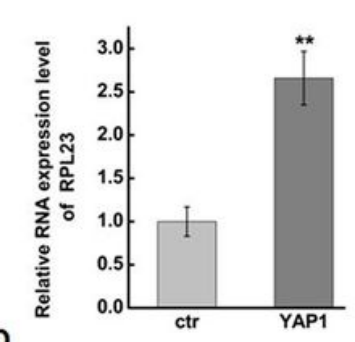

D

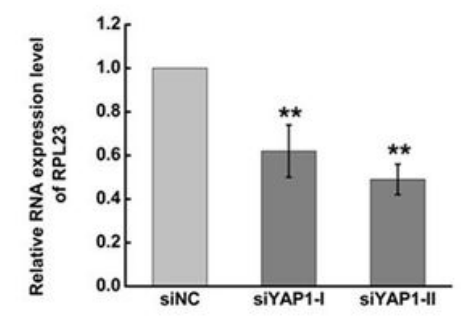

E

F
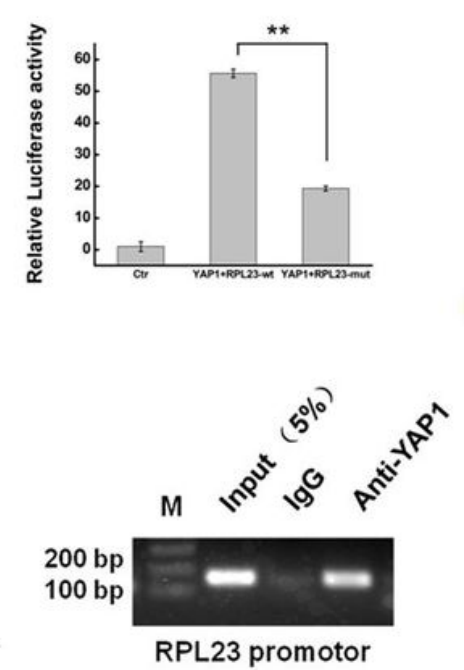

G

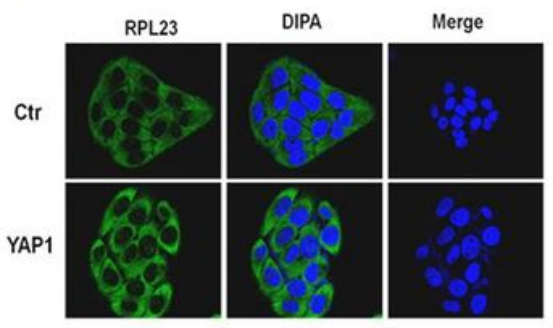

H

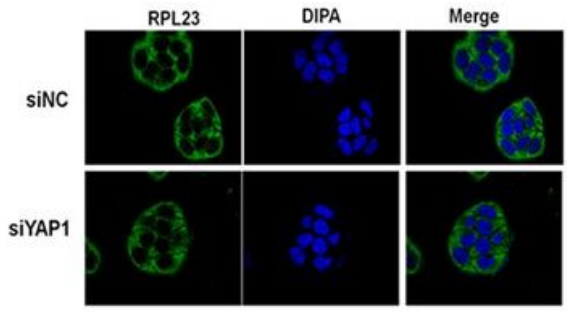

Figure 6

YAP1 promoted the transcription expression of RPL23 by binding the promoter region via TEAD. (A).Western blots analysis of the RPL23 protein expression at $48 \mathrm{hr}$ after overexpressing YAP1 in HeLa cells. (B). qRT-PCR was used to measure the RPL23 RNA level after transfecting pYAP1 at $48 \mathrm{hr}$. (C). The RPL23 protein expression level was measured after YAP1 inhibition at $48 \mathrm{hr}$ by western blotting. (D). qRT-PCR was used to measure the RPL23 RNA level after transfecting siYAP1at $48 \mathrm{hr}$. (E). Dual luciferase assay was used to determine the transcriptional regulation between YAP1 and RPL23. (F). Chromatin immunoprecipitation (ChIP) assay was used to determined the interaction between YAP1 and RPL23 in HeLa cells. Input = 5\% of total lysate. IgG = immunoglobulin G. $(\mathrm{G})(\mathrm{H})$. Representative images showing the distribution of RPL23 in HeLa cells after YAP1 knockdown/overexpression under confocal microscopy. Data are presented as means \pm S.D. and represent results from three independent experiments. Statistically significant differences are indicated: *, $P<0.05 ; * \star, P<$ 0.01 (Student's t test).

A

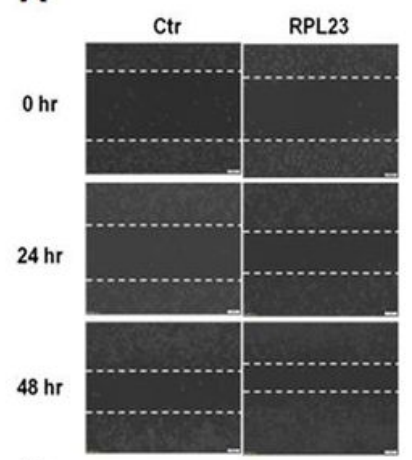

B

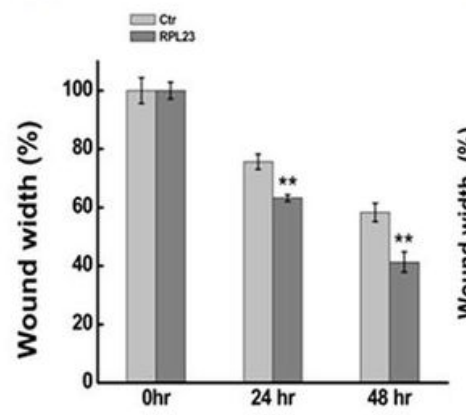

C

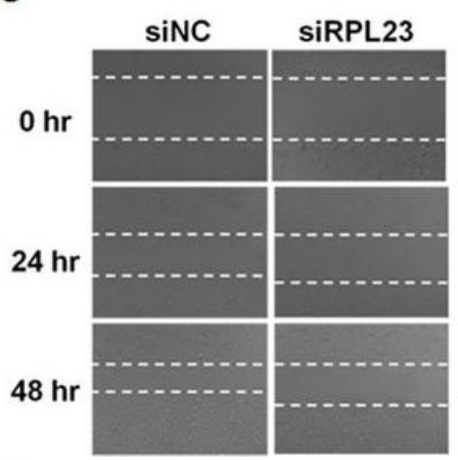

D

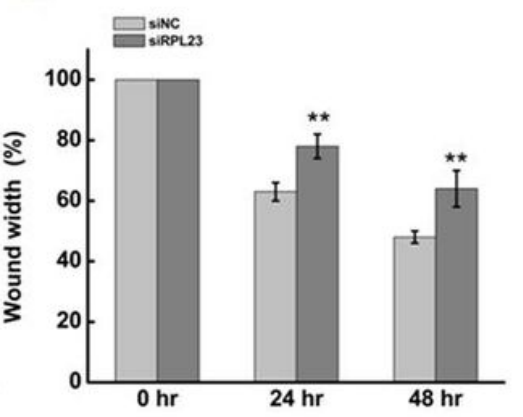

E

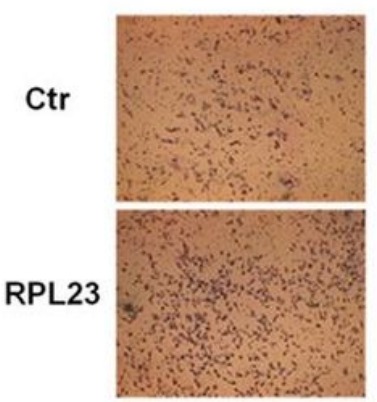

G

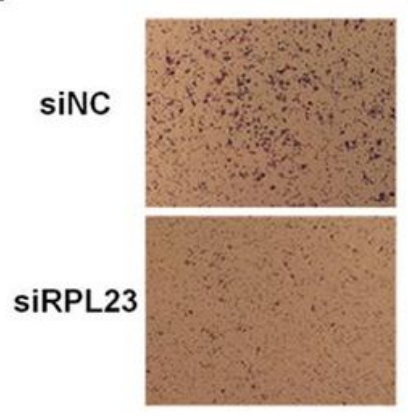

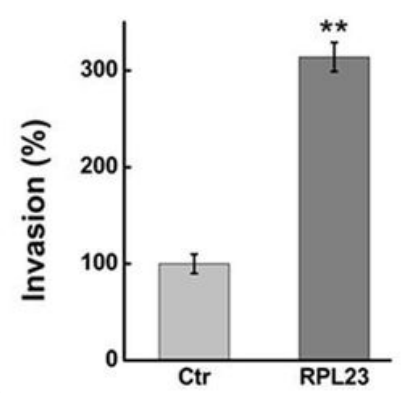

F

H

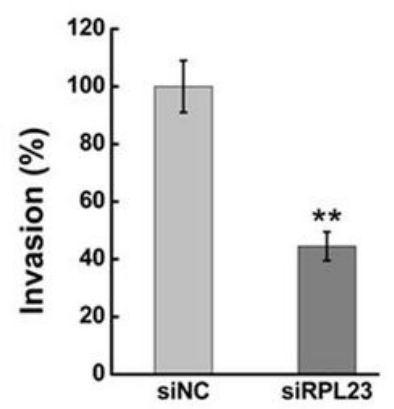

Figure 7 
Effect of RPL23 on cells migration and invasion in HeLa cells. (A). The effect of expression RPL23 on cell migration was determined by wound healing assay. (B). Quantification of the wound healing assay. (C). The effect of RPL23 inhibition on cell migration was determined by wound healing assay. (D). Quantification of the wound healing assay. (E). The effect of RPL23 on cell invasion was determined in a Boyden chamber assay. (F). The number of cells on the underside of the filter was determined. (G). The effect of RPL23 inhibition on cell invasion was determined in a Boyden chamber assay. $(H)$. The number of cells on the underside of the filter was determined. Data are presented as means \pm S.D. and represent results from three independent experiments. Statistically significant differences are indicated: *, $P$ $<0.05 ; * \star, P<0.01$ (Student's $t$ test).

A

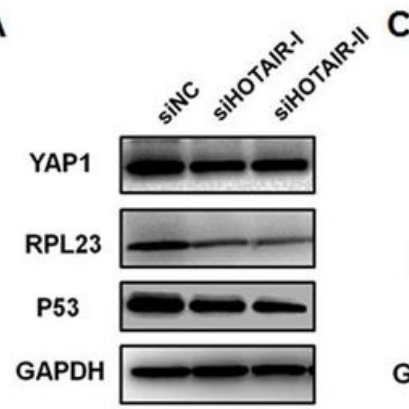

B

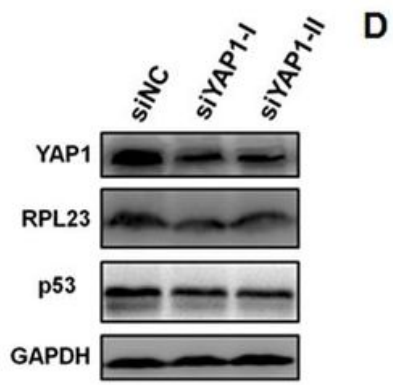

C

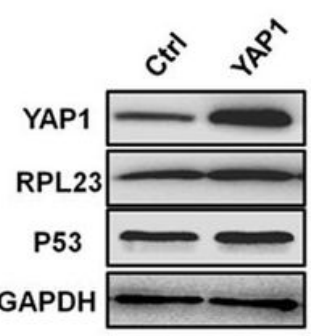

E

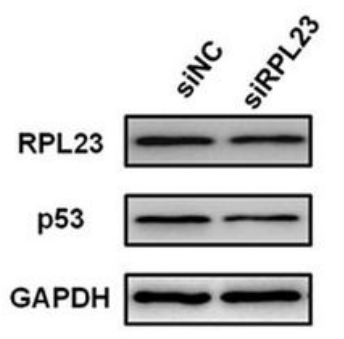

$\mathbf{F}$
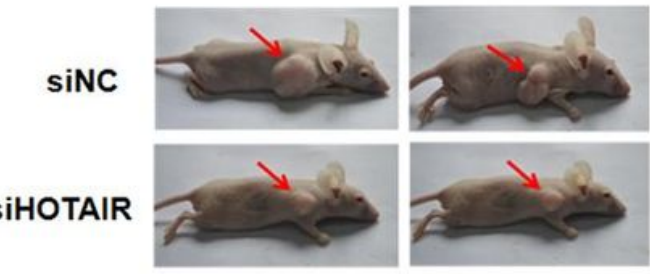

G

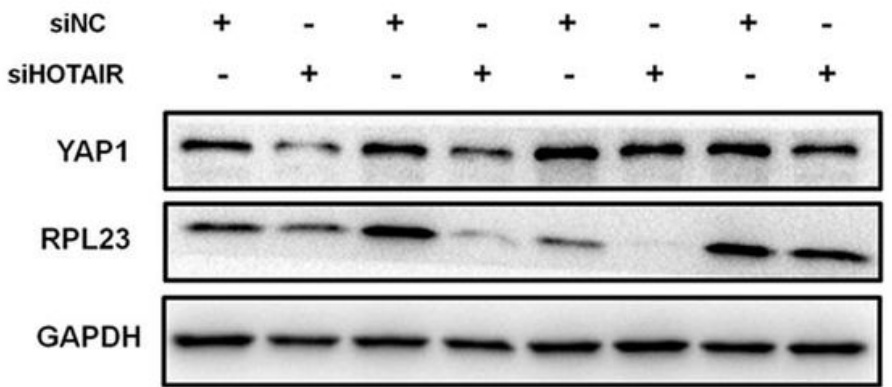

Figure 8

HOTAIR regulated YAP1 and RPL23 expression in nude mice. (A). Western blotting was used to measured YAP1, RPL23 and p53 protein level after HOTAIR inhibition at $48 \mathrm{hr}$ in HeLa cells. (B)(C). RPL23 and p53 were measured at $48 \mathrm{hr}$ after transfecting siYAP1 or pYAP1 in HeLa cells. (D)(E). After Inhibition/overexpressing RPL23 in HeLa cells, p53 protein level was measured by western blotting at $48 \mathrm{hr}$. (F). Representative photographs of xenografts were taken 3 weeks after injection of HeLa cells transfected with siHOTAIR or siNC. (G). Western blotting of YAP1 and RPL23 protein expression in tumors excised from the xenografts mice model.

\section{Supplementary Files}

This is a list of supplementary files associated with this preprint. Click to download.

- TableS1ThesequencesofprimersandsiRNAs.docx 